\title{
A NOVEL MUTATION OF THE ABCD1 GENE IN SERBIAN X-ADRENOLEUKODYSTROPHY
}

\author{
Grkovic $\mathrm{S}^{1 *}$, Nikolic $\mathrm{R}^{2}$, Djordjevic $\mathrm{M}^{1}$, Puzigaca $\mathrm{Z}^{2}$, Vujic $\mathrm{D}^{1}$, Ilic $\mathrm{P}^{2}$
}

*Corresponding Author: Dr. Sanja Grkovic, Department of Pediatrics, Mother and Child Health Care Institute of Serbia, Ljeska 55, 11030 Belgrade, Serbia; Tel.:+38-1641548175; Fax: +38113108276; E-mail: metlab@ sezampro.yu

\begin{abstract}
X-linked adrenoleukodystrophy (XALD), the most common inherited peroxisomal disorder, is characterized by central nervous system demyelination, primary adrenal failure and the systemic accumulation of saturated very long chain fatty acids (VLCFAs). We describe a novel mutation of the $A B C D 1$ gene in a Serbian patient with this disorder. The affected boy developed Addison's disease and neurological symptoms at 6 years of age and had a bone marrow transplant 2 years later. His plasma level of saturated VLCFAs, ratios of C24:0/C22:0 and $\mathrm{C} 26: 0 / \mathrm{C} 22: 0$, were all significantly elevated. Direct sequencing of the $\mathrm{ABCD} 1$ gene detected the point mutation $1519(\mathrm{G}>\mathrm{A})$ in exon 6 , which changes a glycine at position 507 into serine (G507S). This is the first report of genetically confirmed Xadrenoleukodystrophy in Serbia.
\end{abstract}

Key words: $\mathrm{ABCD} 1$ gene, Point mutation, $\mathrm{X}$ linked adrenoleukodystrophy (XALD), Peroxisome.

\section{INTRODUCTION}

Adrenoleukodystrophy (ALD) comprises two genetically determined disorders with a different mode of inheritance, i.e., X-linked (XALD) and neonatal autosomal recessive ALD (1). Both are

1 Department of Pediatrics, Mother and Child Health Care Institute of Serbia, Belgrade, Serbia

2 Department of Gynecology, Mother and Child Health Care Institute of Serbia, Belgrade, Serbia characterized by varying degrees of central nervous system demyelination and adrenal dysfunction as well as systemic accumulation of very long chain fatty acids (VLCFAs, fatty acids with more than 22 carbon atoms). X-linked ALD (MIM 300100) is the most common inherited peroxisomal disorder and is due to mutations or defects in the ABCD1 gene that codes for ALDP (ALD protein) (XALD) which is located in the peroxisomal membrane and functions as a crucial transporter of VLCFAs that are metabolized exclusively in peroxisomes by $\beta$-oxidation. Lacking ALDP, VLCFAs fail to enter the peroxisomes and to be activated to their coenzyme A (CoA) derivatives by VLCFA acyl-CoA synthetase (VLCS) for further catabolism (2). The mechanism of how ALDP and VLCS interact remains to be elucidated. Diagnosis relies on clinical presentation, biochemical findings of primary adrenal failure, elevated plasma level of VLCFAs, characteristic leukodystrophic changes in brain magnetic resonance imaging (MRI) and is complemented by genetic analysis. The ABCD1 gene spans about $22 \mathrm{~kb}$ of DNA on chromosome Xq28 and contains 10 exons. To date, more than 944 $\mathrm{ABCD} 1$ gene mutations have been registered in a database (http://www.X-ald.nl). We have identified a novel mutation in a Serbian family with XALD.

\section{CASE REPORT}

The patient is a 6-year-old boy, the first child of unrelated parents. He was born at 40 weeks gestation by spontaneous delivery. There were no perinatal complications. Physical examination revealed 
increased pigmentation of the lips, tongue and buccal mucosa. Early neurological symptoms were behavioral disturbances, deterioration of vision and impaired auditory discrimination. Our patient had the following biochemical abnormalities: low morning plasma cortisol level $1.0 \mu \mathrm{g} / \mathrm{dL}$ (reference range $5-20 \mu \mathrm{g} / \mathrm{dL}$ ) and an elevated ACTH level of $62.4 \mathrm{ng} / \mathrm{L}$ (reference range $9-52 \mathrm{ng} / \mathrm{L}$ ), respectively. A $1 \mu \mathrm{g}$-short synacthen test showed a peak cortisol response of $6.1 \mu \mathrm{g} / \mathrm{dL}$ (reference range $5-20 \mu \mathrm{g}$ / $\mathrm{dL}$ ), confirming the primary adrenal cortex failure. Fasting plasma VLCFA levels of C22:0, C24:0 and C26:0 were 18.0 (control $22.5 \pm 8.0$ ), 39.8 (control $21.6 \pm 8.0$ ) and $1.5 \mu \mathrm{g} / \mathrm{mL}$ (control $0.35 \pm 0.08$ ), respectively. Ratios of C24/C22 and C26/C22 were significantly elevated at 2.21 (normal $0.74-1.627$ ) and 0.083 (normal 0.014-0.063). Cerebral MRI typically showed extensive demyelination in the occipital periventricular white matter.

\section{MATERIALS AND METHODS}

Genomic DNA was extracted from the peripheral blood leukocytes using a standard phenol-chloroform extraction method (3). The splice junctions and all coding regions of the $\mathrm{ABCD} 1$ gene of the proband were amplified by polymerase chain reaction (PCR) using primers ALDe6-F (5'-CGC TCT CTG GCG TCA GCG-3') and ALDe6-R (5'-TGG TGT TGG TCC TCC CTG-3'). The conditions for
PCR were as follows: initial denaturation for $15 \mathrm{sec}-$ onds at $96^{\circ} \mathrm{C}$, followed by 25 cycles of denaturation for 15 seconds at $96^{\circ} \mathrm{C}$, annealing for 15 seconds at $55^{\circ} \mathrm{C}$ and a final extension for $4 \mathrm{~min}$. at $60^{\circ} \mathrm{C}$. The reaction mixture at final volume $(100 \mu \mathrm{L})$ contained 1X PCR buffer II (PE Applied BioSystems, Foster City, CA, USA), $1.5 \mathrm{mM} \mathrm{MgCl}_{2}, 0.5 \mathrm{M}_{\text {betaine (Sig- }}$ ma, St. Louis, MO, USA), $200 \mu \mathrm{M}$ dNTP, $1 \mu \mathrm{M}$ of each primer, two units Taq polymerase and $100 \mathrm{ng}$ of DNA template. The PCR products were sequenced directly using the Dye ${ }^{\mathrm{TM}}$ Terminator cycle sequencing kit (PE Applied BioSystems). Restriction enzyme digestions were performed using $40 \mu \mathrm{L}$ of the initial PCR products of exon 6 using primers ALDe-F and ALDe6-R, and were incubated at $37^{\circ} \mathrm{C}$ overnight with five units of $H$ haI restriction enzyme. The restriction fragments were separated by $3 \%$ agarose gel electrophoresis under $100 \mathrm{~V}$ for 4 hours.

\section{RESULTS AND DISCUSSION}

Peroxisomal disorders are an extremely heterogeneous group of genetic disorders without strict correlation between clinical picture and biochemical abnormalities. The natural history of the disease course is known to be unpredictable. The analysis of VLCFAs in plasma is necessary as the first screening test for diagnosis of XALD.

Sequence analysis (Figure 1) of the ABCD1 mutant allele in the proband revealed a novel point

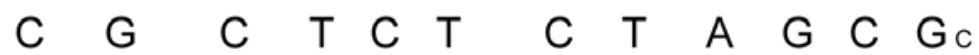 \\ 1519}

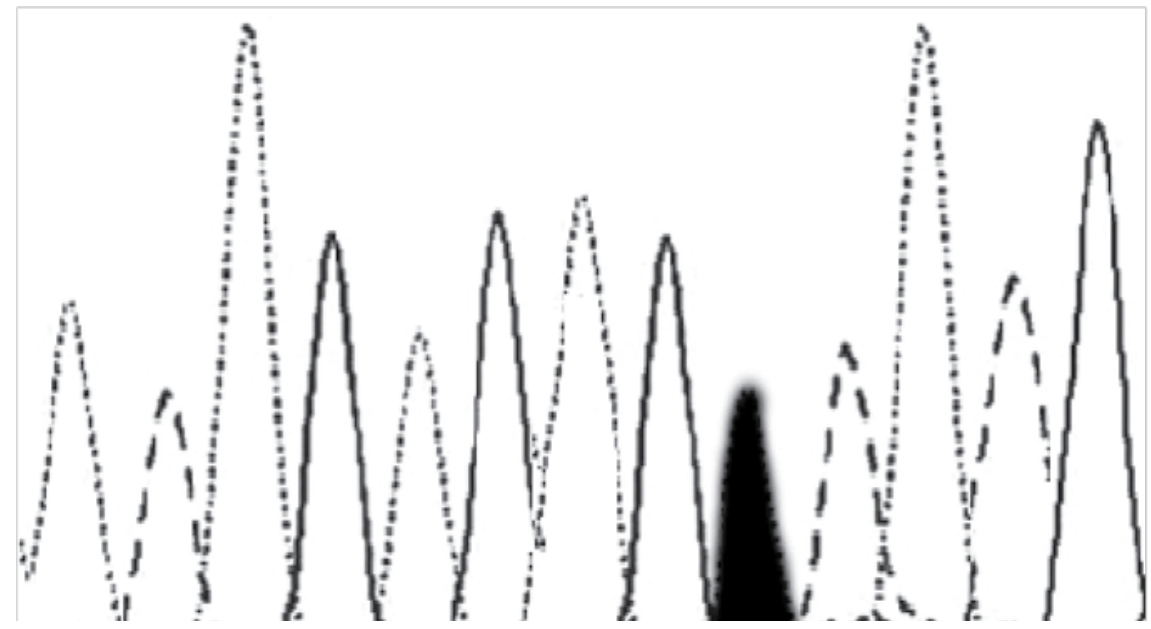

Figure 1. Partial sequence determination of the $1519(\mathrm{G}>\mathrm{A})$ point mutation of the $\mathrm{ABCD} 1$ gene for the hemizygous proband. 
mutation $1519(\mathrm{G}>\mathrm{A})$ in exon 6, causing the change of glycine at position 507 into serine (G507S). So far, no established correlation between genotype and phenotype has been reported (4).

The range of phenotypic expression in XALD and the prognosis for an affected male are unpredictably variable and cannot be predicted through levels of VLCFA in plasma or cultured skin fibroblasts, the residual VLCFA $\beta$-oxidation activity present in XALD skin fibroblasts, the family history or the nature of the mutation identified in the ABCD1 gene of the patient (5). The same mutation can be associated with each of the known clinical phenotypes.

The affected boy had developed neurological symptoms and Addison's disease at 6 years old and a bone marrow transplant at age of 8 without any effect. This mutation in exon 6 caused the changes in the intracellular domain of ALDP and may lead to instability or loss of function of ALDP resulting in accumulation of VLCFAs. Further investigation of ALDP stability in this patient is needed to clarify the impact of this ABCD1 mutation. The childhood cerebral form of XALD is a severe metabolic disease without a definite effective therapy. Mutations in the ABCD1 gene have been identified in the majority of XALD patients, and almost $60 \%$ of mutations are non recurrent. In conclusion, analyses of mutations in patients with XALD is necessary, especially for carrier diagnosis and genetic counseling, since more than 900 different mutations in the gene have been reported.

\section{REFERENCES}

1. Moser W, Smith D, Watkins A, Powers J, Moser B. X-linked adrenoleukodystrophy. In: Scriver CR, Beaudet AL, Sly WS, Valle D, Eds. The Metabolic and Molecular Bases of Inherited Disease, 8th ed. New York: McGraw-Hill. 2001; 3257-3301.

2. Lazo O, Contreras M, Hashmi M, Stanley W, Irazu C, Singh I. Peroxisomal lignoceroyl-CoA ligase deficiency in childhood adrenoleukodystrophy and adrenomyeloneuropathy. Proc Natl Acad Sci USA 1988; 85(5): 7647-7651.

3. Mathew CC. The isolation of high molecular weight eukaryotic DNA. In: Walker JM, Ed. Methods in Molecular Biology, Vol. 11. New York: Human Press. 1984; 31-34.

4. Wichers M, Kohler W, Brennemann W, Boese V, Sokolowski P, Bidlingmaier F, Ludwig M. $\mathrm{X}$-linked adrenoleukodystrophy associated with 14 novel ALD gene mutations: no correlation between type of mutation and age of onset. Hum Genet 1999; 105(2?): 116-119.

5. Kemp S, Pujol A, Waterham HR, van Geel BM, Boehm CD, Raymond GV, Cutting GR, Wanders RJ, Moser HW. ABCD1 mutations and the Xlinked adrenoleukodystrophy mutation database: role in diagnosis and clinical correlations. Hum Mutat 2001; 18(3): 499-515. 
